\title{
CSCL: connecting the social, emotional and cognitive dimensions
}

\author{
Sten Ludvigsen ${ }^{1}$ \\ Published online: 26 May 2016 \\ (C) International Society of the Learning Sciences, Inc. 2016
}

In this issue of $i j C S C L$, a number or core or classical problems are addressed. What I mean by classical problems or themes involve how collaborative efforts emerge and become constituted. To work together, we need to orient ourselves to the other participants in dyads, in small groups, and in larger communities, as well as to the resources at hand. The computational environment in which collaboration occurs should, in principle, support the goals of Sharing and building common ground. When we talk about sharing, we often have a number of assumptions about what this means. Do we mean just the sharing of experiences, or some degree of overlap of mental models or states? Do we mean the sharing of deep cultural patterns anchored in life worlds, or just having people with a common background in the same groups? The meanings of sharing, common ground, or intersubjectivity obviously differ according to the theoretical lenses and epistemological position one takes. However, it is also an empirical phenomenon that we need to examine. Even if interpretations of data are partly dependent on the theoretical assumptions involved, sharing the results and how data are analyzed is important.

The other main theme in this issue is how social interaction and collaboration involve multiple aspects, such as emotional, cognitive, and social dimensions, and how these become worked upon in tasks and in problem solving. Emotions and identities obviously play an important role in collaborative learning. The question then becomes how these are conceptualized and investigated, and what role or function they play when students work face-to-face or interact through asynchronous chat environments. Emotions are gradually being seen as creating some of the conditions for a particular type of engagement or motivation. However, emotions are also a part of the social interaction and cognitive work that is at stake for the participants, which means that one needs to study how emotions contribute to and are coconstituted with the cognitive and social aspects.

Identities or identification can be seen as a part of how individuals position themselves in a group or a community. When working with a particular task, students can choose to participate

Sten Ludvigsen

s.r.ludvigsen@iped.uio.no

1 University of Oslo, Oslo, Norway 
in many different ways, which gives their peers a sign as to how they want to be perceived and how they want to participate. In formally defined groups, students can perform different functions with regard to coordinating, mobilizing, and sharing content and creating summaries. In more open chat environments, students can position themselves as very motivated participants, with a high frequency of epistemic contributions, or as modest participants or even lurkers. By using particular signs and words, students build up a social position within the group. We can say that identities are also strongly related to the motives for participating. Positioning in dialogues is often based on subtle cues that are created in the collaboration turn by turn.

The last theme in this issue addresses group formation and group performance. Although the CSCL community has a strong interest in the relation between group formation and group performance, we have published few contributions in this area. As more and more advanced machine learning techniques and CSCL tools are used in higher education courses, we can expect these studies to bring new insights to the field. We know that students need to collaborate because many of the problems of today and tomorrow are dependent on teams that can solve complex tasks together. Many international agencies have chosen to highlight collaborative problem solving as one of the most important skills in the 21st century. Measuring group composition and individual and group performance implies the use of new methods and techniques in the CSCL community.

The four articles published in this issue reflect the diversity of the field. They include qualitative studies that analyze the relationships between cognitive aspects of collaboration, participants' use of language, and the importance of identification in the social and cognitive work that students undertake. One of the articles analyzes group performance and learning outcomes in an e-learning setting, while another adds new insights about the importance of shared knowledge in mutual modeling.

The papers published in this issue provide new insight into:

- How group emotion functions in argumentation;

- How identification is part of knowledge construction, and what role it plays in the intersection between the personal and the social;

- How we can predict group performance based on advanced machine learning techniques; and

- Whether we need to revise assumptions about common ground and the role it plays in mutual modeling.

The articles:

\section{Social, cognitive, and emotional dimensions of arguing to learn}

Argumentation in CSCL is one of the core areas to which many scholars in the community have contributed. Different perspectives on argumentation and learning become connected and conceptualized in this area (Andriessen and Baker 2014; Harney et al. 2015; Lund et al. 2007; Muller Mirza et al. 2007; Scheuer et al. 2010; Schwarz and De Groot 2007; Schwarz et al. 2015). Studies on argumentation have been conducted for a long period of time in philosophy and language studies. In the formulation of arguments in the classroom or other learning environments, the connection between argumentation and learning is crucial. Argumentation is perceived as an advanced practice that involves knowledge, skills, and socio-emotional stances that need to be cultivated over long stretches of 
time. Given that collaborative argumentation draws on multiple perspectives, examining which aspects are included empirically and what functions they can have is important.

The first article, "Group Emotions: The Social and Cognitive Functions of Emotions in Argumentation" by Claire Polo, Kristine Lund, Christian Platin, and Gerald P. Noccolai, addresses the socio-emotional aspects of collaboration and how they are related to cognition. The social, emotional, and cognitive dimensions are often conceptualized as interrelated. However, it is seldom that all three dimensions are considered in a single empirical analysis. This paper focuses on how the three dimensions are related. The analysis explores argumentation and collaboration from a linguistic perspective and relates the insights back to the CSCL field. The empirical part of the study involves two case studies.

The article position itself in relation to the literature on argumentation and collaborative learning with the purpose of identifying how emotions are considered in these types of studies. The discussion of the literature considers how emotions are included in studies, with regard to focus, method, and object. Additionally, studies examine emotions and how they can be considered individual resources or emerge as part of the collaboration. Emotion might be seen as hampering collaboration, and one might need to develop tools for creating awareness and regulating emotion as part of the collaborative efforts. A key concept is the tonality of the discourse objects, which influence how participants choose to put forward an argumentative claim. The review especially emphasized the three concepts in Mercer and colleagues' work: cumulative, disputational, and exploratory talk. The cumulative and disputational talk is not seen as especially productive for learning, while explorative talk creates conditions for seeing a problem from different perspectives, changing assumptions, moving a line of argument in new directions, which can all contribute to productive learning for the students involved.

The empirical cases reveal that emotion can be connected to types of talk. For example, low-intensity emotional framing is usually related to cumulative talk, and disputational talk is often characterized by high-intensity emotional framing; but there are many interactional phases that can't be classified according to these types of talk. Hence, talk varies from cumulative to exploratory on a continuum.

The model that the authors propose is interesting, and other CSCL researchers could use this model as a framework for analyzing how social, emotional, and cognitive functions interrelate. This does not mean that they are equally important in an interactional sequence. Polo et al. argue that we need to see emotions as part of the ongoing cognitive efforts and make participants aware of how social roles are affected by emotion and how participants need scaffolds that help regulate the collaborative efforts. The practical implication can be to develop and design collaborative learning that recognizes that emotional aspects are often at stake when participants are expected to collaborate in ways that lead to new understanding of difficult and complex conceptual concepts.

\section{Learning as a personal, social, and collective experience}

The socio-cultural perspective is one of the three perspectives on learning that is foundational in CSCL. One can find a number of contributions that emphasize how the collective aspects of learning and dialogues contribute to such formations. In addition, many previous studies, including the editorial of Stahl (2015), argues that we need to analyze data on different social and cultural levels (e.g., Damsa 2014). Specifying how individuals contribute and participate is equally important. This goal can be achieved by choosing a level of description for the analysis 
in which each participant's contribution becomes specified as a part of the socio-cultural context (Enyedy et al. 2015).

In the second article, "Cultural Ways of Constructing Knowledge: The Role of Identities in Online Group Discussions," Murat Öztok takes a distinctly socio-cultural perspective. He recognizes that knowledge construction is a process of collective thinking, but also that we need to understand how participants make use of identification categories as part of the sense-making and knowledge construction. By identification categories, Öztok means that individual participants play out their identities as part of collaborative efforts. Identities, or identification, can be manifested in collaboration in different ways and function as a resource in the knowledge construction of an individual and as part of the collective efforts in groups or larger collectives.

The broader context of the insights this article gives is the discussion within the socio-cultural perspective of how the social and personal are related to each other. This has also been a topic in previous CSCL research (e.g. Arvaja 2012). Öztok argues that the concept of identification can help us understand how personal perspective and the shared meaning of the collective knowledge involved becomes related and connected. The concept of identity has been central in the socialcultural field, but few studies have addressed this phenomenon at the interactional level. Identity is also a concept that has been influential in areas of social sciences (psychology, sociology, and anthropology) and in the humanities (philosophy). For instance, Cress (2005) showed that CSCL tools can have affordances to activate either personal or social identities.

Empirically, the author uses an interaction-analysis model, which includes five phases of interaction that make it possible to capture how identities are displayed in the threaded interactions within a CSCL environment. The study is categorized as a case study, which can provide in-depth insight about a specific phenomenon. The data is selected in order to illustrate how identification is played out. The content in the case study is from the field of education - theories and frameworks for online education from a large North American research university. The participants that are analyzed are carefully presented.

The three cases analyzed indicate an interesting variation with regard to how participants use identification and how this positioning affects the discourse in specific sequences and, over time, the trajectory of the participation. The participants also make use of different identity markers in their trajectories. The use of multiple identifications is an interesting result and important to follow up on. The relationship between multiple identification and knowledge construction is important. This study by Öztok shows that the identification is closely related to how and what knowledge the students construct.

A hypothesis that grows out of this work is that identification can be associated with epistemic agency. The complexity of ideas is dependent on how students engage in activities, which implies how they can execute their epistemic agency. This article adds specification on how individuals perform actions as part of socio-cultural settings and how their knowledge construction is intertwined with other participants and the tools present in these settings. The identification of how a participant acts within socio-cultural settings gives us new insights about how participants position themselves in CSCL settings.

\section{Group composition and group performance}

The formation of groups in CSCL has been an important theme. Studies have analyzed how small groups or teams work together in efficient ways (Isotani et al. 2009; Siqin et al. 2015). A major challenge is relating automatically generated group formation to group efficacy. To do 
so, one needs advanced tools for analyzing and matching students in groups, as well as statistical measures that can capture both individual and group performance (Cress 2008).

The third article, "Quantitative Approach to Collaborative Learning: Performance Prediction, Individual Assessment, and Group Composition" by Ling Cen, Dymitr Ruta, Leigh Powell, Benjamin Hirsch and Jason Ng, addresses a central question in CSCL research. The issue at stake here is how one can measure and predict how groups perform based on group participants' interactions and group composition. This article aims to identify effective grouping mechanisms and to predict group outcomes. The design goal is the implementation of efficient interaction patterns in CSCL systems and the analysis of what motivates students to collaborate and perform academically in dynamic settings.

The empirical settings for the work include courses in higher education, completed over one semester. The content of the courses were Molecular Biology Engineering and Freshman Engineering Design. The analysis builds on two strands of research: education data mining and CSCL. An important part of the review is the description of the complexity involved in collaborative efforts. Inspired by the work of Cress (2008) which argues that in CSCL research, the analysis needs to capture both individual performance outcomes and group outcomes, the authors perform analyses that capture both.

The review of studies in educational data mining and CSCL create a rather complex view of indicators for group performance assessment. Based on a critical discussion of different alternatives, the authors developed a set of indicators for predicting group performance. The empirical analysis shows that it is possible to predict the group's performance based on advanced machine-learning techniques. Today, these techniques are mature enough to be used to support group performance and group composition. The contribution of this paper for the CSCL community is that the authors are able to show, through a quantitative definition of collaboration synergy, a direct measure of the deviation between average individual performance expectation and the actual group assessment. The synergy in the groups depends on students' high diversity of skills, on equal distribution of workload, and on high concurrency of interaction among the participants in the group. It would be very interesting if the results can be replicated in other domains and with other student cohorts.

\section{Shared understanding and mutual modeling}

Concepts and phenomena such as intersubjectivity, common ground, group cognition, shared understanding and scripts are at the core of CSCL research (Stahl 2006; van de Sande and Greeno 2012; Fischer et al. 2013). When collaboration is at stake, sharing and coordinating "something" is important for the execution of actions. Sharing should be seen as a process and something that emerges, but it can also be seen to include articulated aims and goals and as involving stable socio-cultural patterns that participants have appropriated. Participants come to an activity and task with different mental models. When working on a common task their intuitive or more elaborated models need to be coordinated. To understand how another person thinks and reasons is dependent on a number of factors like creating a common understanding of the problem, changing perspectives, and building on other participants' ideas. Emphasizing the mental level of cognition as a part of building common ground for actions is important within many theoretical frameworks.

In the article "The Symmetry of Partner Modelling" by Pierre Dillenbourg, Séverin Lemaignan, Mirweis Sangin, Nicolas Nova, and Gaëlle Molinari, the problem of collaborative 
tasks, degrees of shared understanding, and mutual modeling are addressed. This contribution focuses on two classical problems in the CSCL field: cognitive modeling and the achievement of common ground. First, the authors review and discuss how common ground is conceptualized from different perspectives, and then they explore the problem of representing a model for a partner in the collaboration. The central question here is: Does the quality of the partner model depend on the modeler's ability to represent his or her partner?

The study reports on five experiments in which participants are engaged in collaborative problem solving. The tasks in the five experiments vary in their importance and in how difficult it is to build accurate models. The review of shared understanding shows what it can mean for two participants to develop a common ground differently. This can be due to disparities in theoretical assumptions or what is included in the phenomenon when it is described and analyzed. When we assume that it is the same phenomenon that different research traditions want to understand and explain, we might start to ask other questions. The question that Dillenbourg et al. raises concerns how shared understanding is built and achieved. This question is at the heart of CSCL research, related to the design of collaborative tasks and the analysis of participants' performance in specific settings. The partner modeling is defined as the process of interpreting one's partner's mental states. The authors emphasize the bi-directional character of the model. What is especially interesting in this contribution is the development of a formal notation for mutual modeling. The formal notation is used as a tool for this paper in particular.

The starting assumption for the work of Dillenbourg et al. is that partner modeling is an individual skill, and that such a skill can be improved by using awareness tools. The finding is interesting since it partly contradicts the hypothesis. The quality of the modeling emerges through the task and is sensitive to the awareness of tools and to media richness in the environment. In several, but not all of the experiments, the symmetry of mutual models in the dyad seems to be crucial.

The article raises and contributes to a number of imperative issues in the CSCL community, including how we understand and conceptualize shared understanding, how we interpret and measure such a phenomenon, and next steps for advancing research on mutual modeling.

\section{References}

Andriessen, J., \& Baker, M. (2014). Arguing to learn. In R. K. Sawyer (Ed.), The Cambridge handbook of the learning sciences (pp. 439-460). New York: Cambridge University Press.

Arvaja, M. (2012). Personal and shared experiences as resources for meaning making in a philosophy of science course. International Journal of Computer-Supported Collaborative Learning, 7(1), 85-108.

Cress, U. (2005). Ambivalent effect of member portraits in virtual groups. Journal of Computer Assisted Learning, 21(4), 281-291.

Cress, U. (2008). The need for considering multilevel analysis in CSCL research - an appeal for the use of more advanced statistical methods. International Journal of Computer-Supported Collaborative Learning, 3(1), 69-84.

Damsa, C. I. (2014). The multi-layered nature of small-group learning: Productive interactions in object- oriented collaboration. International Journal of Computer-Supported Collaborative Learning, 9(3), 247-281.

Enyedy, N., Danish, J. A., \& DeLiema, D. (2015). Constructing liminal blends in a collaborative augmentedreality learning environment. International Journal of Computer-Supported Collaborative Learning, 10(1), 7-34.

Fischer, F., Kollar, I., Stegmann, K., \& Wecker, C. (2013). Toward a script theory of guidance in computersupported collaborative learning. Educational Psychologist, 48(1), 56-66. 
Harney, O. M., Hogan, M. J., Broome, B., Hall, T., \& Ryan, C. (2015). Investigating the effects of feedback on argumentation style, consensus and perceived efficacy in collaborative learning. International Journal of Computer-Supported Collaborative Learning, 10(4), 367-394.

Isotani, S., Inaba, A., Ikeda, M., \& Mizoguchi, R. (2009). An ontology engineering approach to the realization of theory-driven group formation. International Journal of Computer-Supported Collaborative Learning, 4(4), 445-478.

Lund, K., Molinari, G., Séjourné, A., \& Baker, M. (2007). How do argumentation diagrams compare when student pairs use them as a means for debate or as a tool for representing debate? International Journal of Computer-Supported Collaborative Learning, 2(2-3), 273-295.

Muller Mirza, N., Tartas, V., Perret-Clermont, A.-N., \& de Pietro, J.-F. (2007). Using graphical tools in a phased activity for enhancing dialogical skills: An example with Digalo. International Journal of ComputerSupported Collaborative Learning, 2(2-3), 247-272.

Scheuer, O., Loll, F., Pinkwart, N., \& McLaren, B. M. (2010). Computer-supported argumentation: A review of the state of the art. International Journal of Computer-Supported Collaborative Learning, 5(1), 43-102.

Schwarz, B. B., \& De Groot, R. (2007). Argumentation in a changing world. International Journal of ComputerSupported Collaborative Learning, 2(2), 297-313.

Schwarz, B. B., de Groot, R., Mavrikis, M., \& Dragon, T. (2015). Learning to learn together with CSCL tools. International Journal of Computer-Supported Collaborative Learning, 10(3), 239-272.

Siqin, T., van Aalst, J., \& Chu, S. K. W. (2015). Fixed group and opportunistic collaboration in a CSCL environment. International Journal of Computer-Supported Collaborative Learning, 10(2), 161-181.

Stahl, G. (2006). Group cognition: Computer support for building collaborative knowledge. MIT Press.

Stahl, G. (2015). A decade of CSCL. International Journal of Computer-Supported Collaborative Learning, 10(4), 337-344.

van de Sande, C., \& Greeno, J. G. (2012). Achieving alignment of perspectival framings in problem- solving discourse. The Journal of the Learning Sciences, 21(1), 1-44. 